\title{
Research on the Development and Construction of Pre - school Education in Village in the City of Shaanxi Province
}

\author{
Ni Li ${ }^{1, a}$ \\ ${ }^{1}$ Shaanxi Xueqian Normal University, Xi'an, Shaanxi, China, 710010 \\ aemail,
}

\begin{abstract}
Keywords: Development, Construction, Pre - school Education, Village in the City, Shaanxi
\end{abstract} Province

\begin{abstract}
As a lag of urbanization products, city village distribute like island in the urban fringe. In order to better understand the situation of the village in the real life, this paper aims at the status quo of the pre-school education in the semi-urban and rural villages in the villages and villages that have been transformed and unmodified in Shaanxi Province.
\end{abstract}

\section{Introduction}

Life hundred years, stand in school. Pre-school education is the foundation of the development of life, is the beginning of school education and lifelong education. Everyone to accept pre-school education is the foundation of the foundation, the overall situation, the pilot project. Looking around the world today, all countries attach importance to pre-school education, universal pre-school education, the development of pre-school education improve the quality of pre-school education as a strategic focus. The quality and level of pre-school education has not only become an important indicator of the progress of a country's civilization, but also an important indicator of a country's ability to measure sustainable development.

However, the development of pre-school education in the city of Shaanxi Province, the following problems: First, prefectural and pre-school education to promote self-financing projects are not in place according to plan; second part of the county is not required by the account management of kindergarten project funds; The construction scale is more than the planned investment of the reform and development departments approved; Fourth, the actual cost of some projects is higher than the market price, the project accounts more than the amount of engineering; Fifth, the construction of the basic construction of the basic construction procedures are not standardized, 6 , kindergarten construction land, all kinds of housing (total gross floor area, the average building area, activities and auxiliary space, the construction of the project, the construction of the project, office space and the use of housing use area, living space use area and construction area) there is no compliance phenomenon; seven is part of the project quality defects, there is leakage of the classroom, wall skin off skin, playground ground, classroom wall there are cracks and other quality problems.

\section{Pre-School Education Three-Year Action Plan}

"The first three years of pre-school education plan," the first proposed in November 2010, "State 10" which: "provinces (autonomous regions and municipalities) government to conduct in-depth investigation, accurate grasp of the basic situation of local pre-school education and the existence of outstanding problems, Combined with the region's economic and social development and the age population distribution, trends, scientific measurement of admission requirements and supply and demand gap, to determine the development goals, decomposition of the annual tasks, the implementation of funds to county pre-school preparation of three years of action plan, Difficult to enter the park.

"Since 2011, in order to implement the" national ten ", the provinces and municipalities to speed up the introduction of the province under the provincial situation or the situation of the" pre-school three-year action plan "2011 to 2013 each year need to complete the pre-school education specific 
tasks decomposition, efforts to solve the pre-school education resources, admission rate is not high, the number of public park is too small, "admission is difficult," admission and other prominent issues. "Shaanxi Provincial People's Government Office of the three years of pre-school education action plan 2011-2013 notice "to speed up the popularization of pre-school education, combined with the actual, to develop and fully promote the three-year pre-school education action plan. February 2011 to March, the provincial government and the city have developed a" pre-school education Three-year action plan ".

\section{The Problems of Prefectural Education Development in the Village in the City of Shaanxi Province}

It Lacks of Rational Thinking about the Supply of Pre-School Education in Urban Villages. Most people think that pre-school education for children in the village is to allow all children to go to kindergarten. Therefore, we usually hope that with the Government to increase, expand kindergarten. In fact, for the city of the above characteristics, the requirements of pre-school education should be more diverse than the city. In general, the average level of education in urban villages is low and there is little social capital and cultural capital to promote the development of children. Even because of the occlusion of information, parents lack scientific knowledge of parenting, relying on traditional customs and experience to educate their children. In this case, pre-school education for children in the city should actually include more content than the city. Throughout the world, "pre-school education and services" is actually a broad word, it includes not only the formal kindergarten education services, but also for disadvantaged children to provide a set of services, such as health services, education services, nutrition services, Family services, community services and so on. The practice of developed countries shows that the integration and diversification of pre - school education services should be the direction of pre - school education reform in urban villages in China.

The Duties of the Government Are Not Clear. Although Chinese relevant policies have made it clear that pre-school education is an important part of basic education, social welfare is an important part of the cause. But for a long time, because some government departments and their leadership on the cause of pre-school education and public welfare is not enough understanding of pre-school education in the education system and social welfare in the important position of the lack of a correct understanding of the development concept, In the process of social transformation and system reform in our country failed to fully consider the pre-school education management system reform, pre-school education management system is far behind the stage of compulsory education management system reform, and thus lead to the duties of the various functional departments clear, power cross, long management, and management level is too low and other breakthroughs.

The kindergarten in the village mainly to the private kindergarten, kindergarten from the administrative and also to the various units or individuals to manage, kindergarten internal administrative decentralization, the kindergarten in some areas of education and administrative departments straight, and the tube, the other In addition, the management system is more complex and no custom, there is no stability of the early childhood education management departments and personnel, are classified in the basic education sector, there is no separate pre-school education management or departmental management. So that the outcome is caused by a problem cannot find the person in charge, we shirk responsibility and there is no way to "who is responsible for the management."

Health Funding for Prenatal Education Is Very Low. From the investment point of view, China so far, there is no legislation to raise funds for children's education specifically listed, the state of pre-school investment in the proportion of funding, it is not enough. As the provincial, city and county finance at all levels have focused on the "two basics", therefore, there is little stability in pre-school funding. And the extent to which the education sector's funding for early childhood education depends on the will of the government and the economic and financial situation of the Government in that year. If the leaders of the government are very important to the importance of pre-school education, they may increase their investment. It is possible that the government's 
financial money this year on the point, no next year, no dial, and so on, so the various regions of the investment in early childhood education with great arbitrariness and instability. Chinese management of pre-school education is the implementation of the "local responsibility, hierarchical management and the division of labor departments responsible for the management system and pattern" experienced a decentralization to decentralization and direct management to indirect management, although given the local management of great freedom, Central and provincial government departments are not aware of the local government's financial resources and capacity, while the central and provincial departments have also overlooked their senior leadership and direct management of the right, pre-school education in all regions is mainly inspection, supervision and administration order, did not develop a detailed pre-school education development plan and the standard system, the lack of overall management of the local sector.

Pre-School Education Fees Are Not Standardized. For a long time, pre-school funding has been low. From the overall situation of the country, among the total amount of education funds in the country, pre-school education funding accounted for about the overall level of investment is very low. From the investment and use of funds, the state did not separate the budget of pre-school education. Pre-school education has been included in the primary and secondary education budget, the use of such a system makes the development of pre-school education lack of basic funding protection. From the use of funds, the only funds mainly to the public kindergarten, which led to the development of kindergarten is not balanced. Because of the government's capital investment, low fees, public kindergarten teachers, facilities and equipment is good, which led to a higher rate of office kindergarten, urban students on the public park of the higher enthusiasm. However, in the villages in the city, due to the small number of public kindergartens, combined with the limited investment in urban villages, the overall number and conditions of public parks are low and the only kindergarten cannot meet the needs of the village parents and children. Many parents for children to accept early education choose to send the child near the local private kindergarten.

\section{Suggestions on the Development and Construction of Preschool Education in the Village in the City of Shaanxi Province}

Enhance the utilization of hardware facilities, the use of urban villages in the local resources. On the one hand, the park's principals and township kindergarten management cadres as a senior management should be sober, "for children to use", "to make children in the subtle development" is the hardware resources of the final "foothold." Supervision and inspection of the staff is to stick to their duties, not only concerned about the object is not complete, but should be the hardware resources "utilization" as an important indicator when the inspection, in addition to routine inspection, you can do some occasional "micro service Private visit "to prevent cheating. On the other hand, as a front-line teacher, in the organization of children's daily life, we must actively try to have a variety of materials, equipment, regional, department rooms and so on in their own curriculum goals, if there are middle managers, You can unified planning, guidance, supervision. In the final analysis, every person engaged in early childhood education must have children understand early childhood education, really for the development of children to decision-making and implementation.

Strengthen and standardize the kindergarten management system and management measures. The education department is the pre-school education department, is also the city village pre-school education healthy development organization security should give full play to its leading function. Whether it is in the specialized agencies, or in the unified management of basic education in the office, we must strengthen the management of township education management cadres, clear and perform the pre-school education management responsibilities, can be classified classification management, according to the local pre-school education development the specific circumstances, the development of development plans, and assigned to the relevant executives to complete the specific guidance, supervision, layers of implementation.

Strict kindergarten teachers, principals access system, to carry out targeted teacher training. The result of the expansion of kindergarten is the shortage of kindergarten teachers, which seriously 
affects the quality of kindergarten education and teaching. Especially, there is a serious shortage of staff in kindergartens in the village, and all kinds of kindergarten teachers in the community cannot meet the number of kindergarten teachers Real demand, so it is easy to cultivate a "good enough" unqualified teachers.

Form education together, regularly carry out various forms of home cooperation projects to overcome the "primary school" tend to we know that the supervision of the higher level is not enough, the level of professionalism teachers uneven, the social demands of many factors make the city village public kindergarten Teachers in education and teaching only focus on basic knowledge and skills, the development of children's feelings and attitudes far from educational goals, the choice of educational content on the obvious "primary school" tendencies. As mentioned above, in the higher authorities in the kindergarten supervision mechanism in the implementation of the classification and classification management, responsible for the city in the village of early childhood education business guidance management cadres should strengthen the city village kindergarten education and teaching supervision and evaluation, the establishment of the village Kindergarten "security management" "teaching activities" of the restraint mechanism, timely detection and correction of improper educational behavior, and give the correct demonstration, standardize the park behavior. Superiors cannot notice the situation in the kindergarten from time to time, from time to time unannounced visits and field tracking, the implementation of real and effective supervision, to understand the kindergarten education and teaching activities of the existing problems, so that kindergarten will always perfect education and teaching everywhere. It is worth mentioning that the kindergarten here is not limited to public kindergartens, but also includes the city village private kindergarten teaching activities to check to prevent the virgin between the kindergarten contest "to ensure the overall quality of pre-school education to enhance.

\section{Conclusion}

From the overall quality and ability, the overall quality of the teachers in the village kindergarten is generally low and it is difficult to adapt to the development needs of urban kindergartens. Therefore, all levels of government in Shaanxi Province should pay more attention and efforts to make the urban school pre-school education conditions and school quality to improve and improve the realization of the township level above the public kindergarten full coverage, narrowing the urban and rural pre-school education gap, promote education Balanced development, effectively alleviate the "admission difficult", "admission expensive" problem, greatly improved the child's admission environment, and achieved good social benefits.

\section{Acknowledgements}

Fund Project: Shaanxi Preschool Normal University Research Fund Project (2015YBKJ016)

\section{References}

[1] Huang Fanzhang. Government-led borders and paths - and reshaping the SASAC and the establishment of the National Resources Commission [J]. People's Forum • Academic Front. 2012 (10)

[2] Gao Yanyan. How should "supervise" conduct in the process of government-led pre-school education [J]. Journal of Luliang Institute of Education. 2012 (02)

[3] Er Jiang, Luo Yongle. Public Goods Theory from the perspective of the urban middle school in Guangxi pre-school education supply analysis - A case study of Ximing Village in Nanning City [J]. Market Forum. 2012 (01) 
[4] Zhang Tao, Tang Hehua. Government-led to promote the development of pre-school education in urban villages - based on the balanced development of education perspective [J]. Contemporary pre-school education. 2011 (04)

[5] Yang Dongmei, Li Hui, Dai Mingli.Strengthen the government-led, innovation system mechanism - Shandong Province to vigorously promote the city's pre-school education popularization experience and enlightenment [J]. Pre-school education. 2011 (11)

[6] Li Tianshun. Public welfare preschool education lay the foundation for the future [J]. People's Education. 2011 (11) 